New Developments in Sheep Production

Occasional Publication No. 14-British Society of Animal Production 1990

edited by C. F. R. Slade and T. L. J. Lawrence

\title{
AN ANALYSIS OF ULTRASONIC FAT AND MUSCLE MEASUREMENTS IN HILL EWE AND RAM LAMBS
}

\author{
I. AP DEWI ${ }^{1}$, J. B. OWEN ${ }^{1}$ and G. LL. WILLIAMS ${ }^{2}$ \\ ${ }^{1}$ School of Agricultural and Forest Sciences, University College of North Wales, Bangor, Gwynedd \\ ${ }^{2}$ Camda Cynwyd Ltd, 8 Maes Yr Hafod, Menai Bridge, Gwynedd
}

\section{INTRODUCTION}

$\mathbf{T}$ here is increased consumer demand for reduced fat levels in meat, and farmers are being encouraged to respond to this demand by producing lambs within defined fatness and conformation classes (Kempster, 1989). Selection of breeding stock is important in the attainment of these standards and there is interest in the use of continental and hybrid terminal sire breeds, or of selected individuals from traditional breeds, that will confer to their progeny the desired fat and conformation characteristics. The possibilities that exist for increasing carcass weight, at a given level of fatness, by breed substitution were discussed by Kempster, Croston, Guy and Jones (1987)

The Meat and Livestock Commission (MLC) has introduced a commercial scheme for recording live weight, fat and muscle depth in rams, from which a selection index is calculated (MLC, 1989b). The appropriateness of this technique for selecting within terminal sire breeds has been demonstrated (Simm, Young and Beatson, 1987; Parratt and Simm, 1987). However, there is a need to evaluate its use in hill breeds, where decisions regarding selection of male and female replacements include the consideration of breeding ewe characteristics in addition to marketed lamb characteristics.

\section{MATERIAL AND METHODS}

Fat and muscle depth were recorded using a Concept$\mathrm{L}$ real-time ultrasonic scanner utilizing a $7.5 \mathrm{mHz}$ tranducer. Scanning was performed by operatives from

TABLE 1

Sources of animals used in the study Source $\dagger$ Scanning date No.

Ram
lambs $\left\{\begin{array}{lll}\text { CAMDA flock } & \text { 25 May 1988 } & 49 \\ \text { CAMDA flock } & \text { 17 April 1988 } & 49 \\ \text { Commercial flocks } & \text { 17 April 1989 } & 88\end{array}\right.$

Ewe

lambs CAMDA flock 3 May $1989 \quad 211$ the MLC according to their defined procedure (MLC, $1989 \mathrm{~b})$. The animals used are described in Table 1.

The CAMDA flock is the nucleus unit of a commercial group breeding scheme (MLC, 1989a). The monitored rams were from the nucleus flock of the scheme whilst the ewe lambs included replacements from the nucleus and from a smaller flock used as a genetic control. The 'commercial' rams include individuals from 43 Welsh Mountain flocks in North Wales. Twenty-eight farms contributed only one ram each, seven farms contributed two rams each and the remaining eight farms contributed between four and 10 rams each.

The CAMDA and other commercial rams were overwintered at the University College of North Wales' College Farm as part of a performance test. The ewe lambs were scanned 5 weeks after returning from wintering at a lowland site. They had grazed unimproved hill pasture in the period immediately before scanning. In the CAMDA flock, details of age, number reared, dam age and sire were available but only data on muscle, fat and live weight were available for the lambs from other commercial flocks

Preliminary analysis of the data was performed using the MINITAB statistical package. Detailed analysis of variance was performed using Harvey's mixed model least-squares and maximum likelihood computer program (Harvey, 1985). The analysis of variance for ewes included estimates of the effects of sire, number reared (i.e. type of birth of lamb examined), and of dam age. Number reared and dam age were included since the MLC (1989b) have noted the effect of these variables on ultrasonic fat and muscle depth. Lamb age, lamb live weight and either lamb fat or muscle depth, as appropriate for the analysis of muscle and fat respectively, were included as covariates. For CAMDA ram lambs, the analysis also included the effect of year. The effect of sire was examined within year since rams in the CAMDA flock are only used once, at about 18 months of age, and sires were therefore nested within the years examined. The models used for analysing ewe and ram data were models 2 and 3 respectively of Harvey (1985). 
TABLE 2

Summary of available data

Source

Ram lambs

$\begin{array}{ll}\text { CAMDA } 1988 & \left\{\begin{array}{l}\text { Weight }(\mathrm{kg}) \\ \text { Fat }(\mathrm{mm}) \\ \text { Muscle }(\mathrm{mm}) \\ \text { Age (days) } \\ \text { No. reared } \\ \text { Dam age (years) }\end{array}\right. \\ \text { CAMDA } 1989 & \left\{\begin{array}{l}\text { Weight (kg) } \\ \text { Fat (mm) } \\ \text { Muscle (mm) } \\ \text { Age (days) } \\ \text { No. reared } \\ \text { Dam age (years) }\end{array}\right. \\ \text { Commercial } \\ \text { flocks } 1989\end{array}$

Ewe lambs

No. of Uncorrected
observations mean

48

49

49

49

49

48

49

49

49

49

49

49

88

$$
\begin{array}{r}
52 \cdot 02 \\
4 \cdot 39 \\
26 \cdot 10 \\
416.71 \\
1 \cdot 47 \\
3.63 \\
51.47 \\
3.64 \\
24 \cdot 00 \\
377.94 \\
1.43 \\
3.65 \\
52.02 \\
3.66 \\
24.43
\end{array}
$$

$$
\begin{array}{r}
29 \cdot 96 \\
2 \cdot 15 \\
20 \cdot 69 \\
389 \cdot 89 \\
1.58 \\
3.53
\end{array}
$$

$\begin{array}{rrr}\text { Minimum } & \text { Maximum } & \text { s.d. } \\ & & \\ 42 \cdot 00 & 64 \cdot 00 & 4 \cdot 526 \\ 2 \cdot 00 & 6 \cdot 50 & 0 \cdot 871 \\ 23.00 & 30 \cdot 50 & 1 \cdot 674 \\ 403.00 & 431 \cdot 00 & 7 \cdot 620 \\ 1.00 & 2 \cdot 00 & 0 \cdot 504 \\ 2 \cdot 00 & 9 \cdot 00 & 1 \cdot 734 \\ 41.00 & 60 \cdot 00 & 4 \cdot 528 \\ 1.70 & 5 \cdot 00 & 0 \cdot 818 \\ 18.00 & 28 \cdot 00 & 2 \cdot 282 \\ 394.00 & 373 \cdot 00 & 8 \cdot 370 \\ 1.00 & 3.00 & 0 \cdot 540 \\ 2.00 & 6.00 & 1 \cdot 128 \\ 41.00 & 62 \cdot 00 & 4.614 \\ 1.00 & 9 \cdot 00 & 1.059 \\ 19.00 & 30.00 & 2 \cdot 313\end{array}$

$\begin{array}{rrr}20.00 & 37 \cdot 00 & 2 \cdot 793 \\ 1.00 & 4 \cdot 70 & 0 \cdot 813 \\ 16 \cdot 00 & 26 \cdot 00 & 1.886 \\ 361 \cdot 00 & 419 \cdot 00 & 7 \cdot 620 \\ 1.00 & 3 \cdot 00 & 0.514 \\ 2.00 & 7 \cdot 00 & 1.353\end{array}$

\section{RESULTS}

The data available for ram and ewe lambs are summarized in Table 2 . The mean live weight, fat and muscle depth for all rams was $51.9 \mathrm{~kg}, 3.8 \mathrm{~mm}$ and $24.8 \mathrm{~mm}$ respectively. The observations for the three variables ranged from 41 to $64 \mathrm{~kg}, 1.0$ to $9.0 \mathrm{~mm}$, and 18 to $30 \mathrm{~mm}$ with standard deviations of $4.55 \mathrm{~kg}, 1.00 \mathrm{~mm}$ and $2.30 \mathrm{~mm}$ respectively. The CAMDA rams scanned in 1988 were $0.55 \mathrm{~kg}$ heavier than those scanned in 1989 and also had greater fat and muscle depth $(+0.75 \mathrm{~mm}$ and $+2.10 \mathrm{~mm}$ respectively). It should be noted however that in 1988 , the rams were scanned later giving mean ages at scanning of 417 and 378 days in 1988 and 1989 respectively. Rams from the commercial flocks gave mean live weight, fat and muscle measurements similar to those for the CAMDA rams in the same year, although the variance of observed values was greater for the commercial flock animals. This was particularly noticeable for fat depth.

The relationships between fat and live weight and between muscle and live weight are shown in Figure 1. The correlation coefficient ( $r$ ) and regression equations obtained for these relationships are given in Table 3 . For all ram groups significant $(P<0 \cdot 001)$ correlations $(r)$ of 0.333 and 0.440 were obtained for the relationships between fat and live weight and between muscle and live weight respectively. Similarly, significant $(P<0 \cdot 001)$ correlations $(r)$ of 0.458 and 0.351 respectively were obtained for ewe lambs. Although the correlations for the analysis of all ram data were significant it is noteworthy that correlations coefficients were larger in the 1989 groups than in the combined analysis, and were smaller and not significant in $1988(P>0.05)$.

In order to examine in more detail the factors affecting fat and muscle depth, and to test whether the apparent correlation was due to other common factors, analysis of variance was performed on fat and muscle depth for CAMDA ram and ewe lambs as described earlier. The probabilities for all the factors included in the models are given in Table 4 .

Of the factors examined, the effects of sire and lamb weight gave the lowest probabilities $(P<0.01$ (except for ram muscle analysis) and $P<0.2$ respectively), although number reared gave a probability less that of the sire effect in the analysis of muscle depth in ram lambs. The generally non-significant $(P>0 \cdot 2)$ effect of dam age and number reared on fat and muscle depths, compared with MLC results (MLC, 1989b), may be due to the older age at scanning of the animals used in the current study, relative to MLC scanning recommendations. Since these factors gave comparatively high 

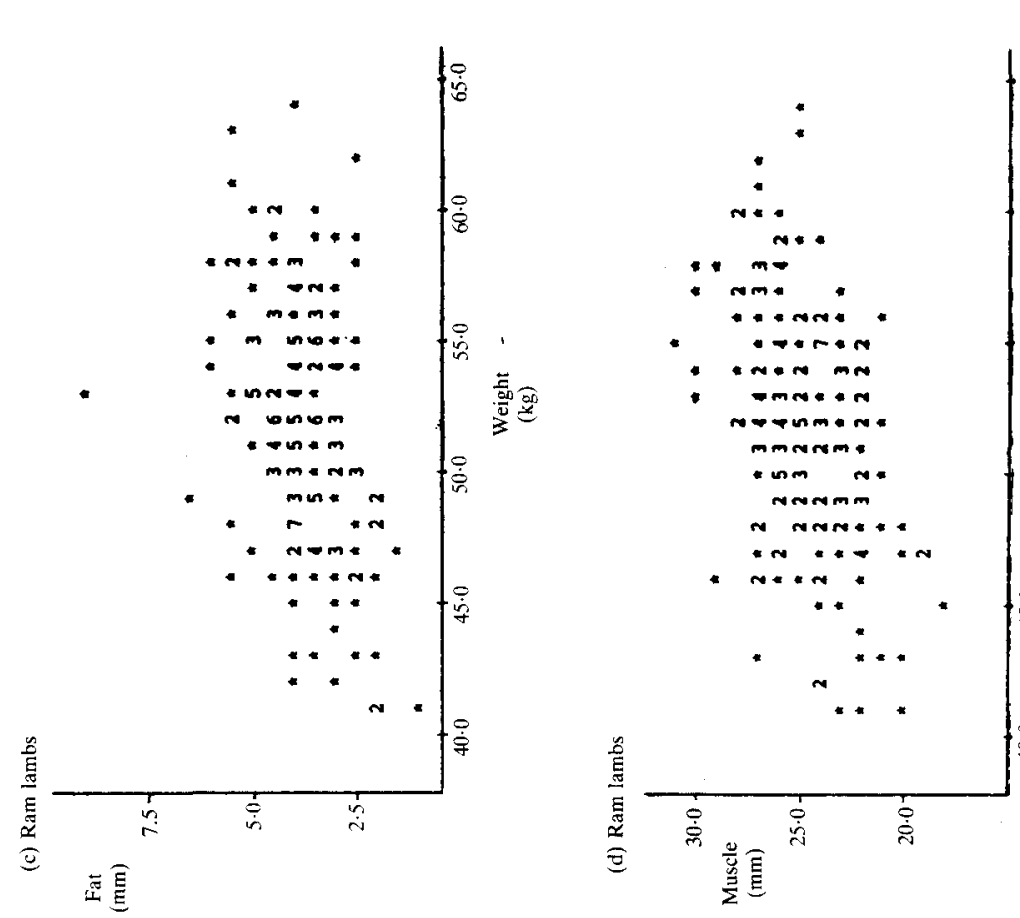

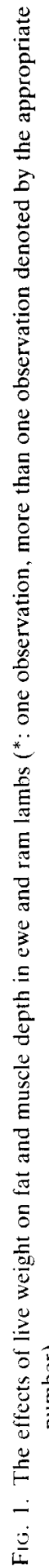


TABLE 3

Correlation coefficients (r) and regression coefficients and constants for prediction equations for the relationships between fat and live weight and between muscle and weight

\begin{tabular}{|c|c|c|c|c|c|}
\hline Source & & $r$ & Constant & $b$ & $\begin{array}{l}P \text { from } \\
\text { regression } \\
\text { analysis }\end{array}$ \\
\hline \multicolumn{6}{|c|}{ Fat $v$. live weight } \\
\hline \multirow{4}{*}{ Ram lambs } & CAMDA 1988 & $0 \cdot 172$ & $2 \cdot 66$ & 0.0334 & $0 \cdot 241$ \\
\hline & CAMDA 1989 & 0.482 & $-0 \cdot 84$ & 0.0870 & $0 \cdot 001$ \\
\hline & Commercial flocks 1989 & $0 \cdot 368$ & -0.73 & $0 \cdot 0845$ & $0 \cdot 001$ \\
\hline & All rams & $0 \cdot 333$ & -0.04 & 0.0735 & $0 \cdot 001$ \\
\hline Ewe lambs & CAMDA 1989 & $0 \cdot 458$ & $-1 \cdot 85$ & $0 \cdot 1340$ & $0 \cdot 001$ \\
\hline \multicolumn{6}{|c|}{ Muscle $v$. live weight } \\
\hline \multirow{4}{*}{ Ram lambs } & CAMDA 1988 & $0 \cdot 167$ & $22 \cdot 9$ & $0 \cdot 062$ & $0 \cdot 255$ \\
\hline & CAMDA 1989 & 0.470 & $11 \cdot 8$ & $0 \cdot 237$ & $0 \cdot 001$ \\
\hline & Commercial flocks 1989 & $0 \cdot 572$ & $9 \cdot 5$ & $0 \cdot 287$ & $0 \cdot 001$ \\
\hline & All rams & $0 \cdot 440$ & $13 \cdot 3$ & $0 \cdot 221$ & $0 \cdot 001$ \\
\hline Ewe lambs & CAMDA 1989 & $0 \cdot 351$ & $13 \cdot 6$ & 0.237 & 0.001 \\
\hline
\end{tabular}

TABLE 4

Probabilities, from least-squares analysis of variance, of fat and muscle depths

\begin{tabular}{|c|c|c|c|c|}
\hline \multirow[b]{2}{*}{ Factor } & \multicolumn{2}{|c|}{ Ewe lambs } & \multicolumn{2}{|c|}{ Ram lambs } \\
\hline & Fat & Muscle & Fat & Muscle \\
\hline Year & & & $0 \cdot 1269$ & 0.3156 \\
\hline Sire $†$ & $0 \cdot 0031$ & $0 \cdot 0303$ & $0 \cdot 0858$ & $0 \cdot 1852$ \\
\hline Number & & & & \\
\hline reared & $0 \cdot 2883$ & 0.5224 & 0.9578 & $0 \cdot 0793$ \\
\hline Dam age & 0.7477 & 0.2938 & 0.6902 & 0.9259 \\
\hline Lamb age & $0 \cdot 6782$ & 0.2858 & 0.9769 & 0.6630 \\
\hline Lamb weight & 0.0000 & 0.0002 & 0.0064 & 0.0737 \\
\hline Fat depth & & 0.2322 & & 0.6525 \\
\hline Muscle depth & 0.2322 & & 0.6525 & \\
\hline
\end{tabular}

$\dagger$ Within year for ram analysis.

probabilities $(P>0 \cdot 2)$ they were not examined further. The effect of year in the analysis of ram fat depth $(P<0 \cdot 1269)$ was noted earlier.

The effect of sire

The effect of sire on progeny fat and muscle measurement is summarized in Table 5. The results reveal a wide range of mean progeny group fat and muscle depth. Although the effect of sire was identified as an important factor influencing fat and muscle depth, particularly for ewe lambs, it is noteworthy that significant differences between sire progeny groups were only found when comparing the lowest and highest progeny group means $(P<0 \cdot 05)$.

\section{The effect of source of rams}

One-way analysis of variance was used to estimate the effect of source of rams. A subset of data containing fat, muscle and live weight information for all rams from commercial farms (including CAMDA) was prepared. Only data from farms for which at least four rams were available were used. Nine farms satisfied this criterion. The means for each farm are shown in Table 6 . Neither live weight, fat or muscle depth were markedly affected by source of rams. The variate showing most variation between farms was lamb weight for which the effect of farms was not significant $(P>0 \cdot 05)$

\section{DISCUSSION}

Analysis of data from 186 ram lambs and from 211 ewe lambs, ranging from 12 to 14 months of age, identified factors affecting fat and muscle depth measured by ultrasonic scanning. Mean live weight, fat depth and muscle depth of $51.9 \mathrm{~kg}, 3.8 \mathrm{~mm}$ and $24.8 \mathrm{~mm}$ respectively were obtained for ram lambs with corresponding values of $30.0 \mathrm{~kg}, 2.2 \mathrm{~mm}$ and $20.7 \mathrm{~mm}$ for ewe lambs. For both ram and ewe lambs, the three recorded variables exhibited substantial variation (Table 2). Analysis of the relationships between fat, muscle and live weight revealed a significant (generally at $P<0.001$ ) effect of weight on fat and muscle depth. This agrees with the positive effects of live weight on a range of carcass measurements found by Bennett (1989). Correlation coefficients ( $r$ ) of between 0.33 and 0.46 were obtained for the relationships between these variables. These are comparable to the phenotypic correlations found by Simm and Dingwall (1989) for the 
relationship between ultrasonic fat depth and live weight and between ultrasonic muscle depth and live weight. The regression of fat on weight (Table 3 ) suggests that fat depth increased by $0.07 \mathrm{~mm}$ and $0.13 \mathrm{~mm}$ for each $\mathrm{kg}$ increase in live weight of rams and ewes respectively. Similarly, muscle depth increased by $0.22 \mathrm{~mm}$ and $0.24 \mathrm{~mm}$ for each $\mathrm{kg}$ increase in live weight of rams and ewes respectively.

The results of least-squares analysis of variance (Table 4) demonstrate that live weight was generally the most important factor affecting both muscle and fat depth. The other factor having a detectable effect was that of sire $(P<0 \cdot 10)$. This implies that both fat and muscle depth are influenced by genetic factors. However, heritability and genetic correlations were not calculated in the current analysis because of the relatively small number of progeny records available for each sire. It is noteworthy that significant differences $(P<0.05)$ existed only between sires with the highest and lowest mean progeny fat and muscle depths.

The results suggest that there exists, within the Welsh Mountain breed, a range of fat and muscle depths. It is also evident that there is substantial variation within flocks, since significant differences $(P<0.05)$ between flocks could not be detected (Table 6). The range of results obtained and the differences between some sire progeny groups suggest that it may be possible to select individuals within hill flocks on the basis of indices incorporating fat and muscle depth measurements. However, the development of a suitable index should include consideration of, firstly, the stong correlation between live weight and both fat and muscle depth. In recent years there has been a trend for Welsh Mountain sheep producers to increase the weight of animals in

TABLE 5

Summary of the effect on sire of progeny fat and muscle depth (CAMDA data only)

Source of data

$\begin{array}{cc}\begin{array}{c}\text { Ram lambs } \\ 1988+1989\end{array} & \text { Ewe lambs } \\ 21 & 1989\end{array}$

No. of sires

$4 \cdot 62$

$9 \cdot 81$

per sire

Fat depth (mm)

Minimum progeny group mean (s.e.) $\quad 3 \cdot 01( \pm 0 \cdot 248) \quad 1 \cdot 50( \pm 0 \cdot 500)$

Maximum progeny group mean (s.e.) $\quad 4.89( \pm 0.286) \quad 3.00( \pm 0 \cdot 258)$

Muscle depth (mm)

Minimum progeny group mean (s.e.) $21 \cdot 00( \pm 1 \cdot 528) \quad 18 \cdot 67( \pm 0 \cdot 667)$

Maximum progeny group mean (s.e.) $27 \cdot 17( \pm 0 \cdot 494) 22 \cdot 46( \pm 0 \cdot 692)$
TABLE 6

The effect of ram source on live weight, fat depth and muscle depth

\begin{tabular}{|c|c|c|c|c|c|c|c|}
\hline \multirow{2}{*}{$\begin{array}{l}\text { Source } \\
\text { (farm) }\end{array}$} & \multirow[b]{2}{*}{ No. } & \multicolumn{2}{|c|}{ Weight (kg) } & \multicolumn{2}{|c|}{ Fat $(\mathrm{mm})$} & \multicolumn{2}{|c|}{ Muscle (mm) } \\
\hline & & Mean & s.e. & Mean & & Mean & \\
\hline 1 & 6 & $48 \cdot 00$ & $1 \cdot 590$ & 3.45 & 0.426 & $23 \cdot 50$ & 0.719 \\
\hline 2 & 97 & $51 \cdot 74$ & 0.458 & $4 \cdot 01$ & $0 \cdot 093$ & 25.05 & 0.228 \\
\hline 3 & 10 & $53 \cdot 40$ & $1 \cdot 240$ & $3 \cdot 78$ & $0 \cdot 372$ & $24 \cdot 80$ & 0.786 \\
\hline 4 & 4 & $48 \cdot 50$ & 1.550 & $4 \cdot 25$ & $1 \cdot 590$ & $22 \cdot 00$ & $1 \cdot 290$ \\
\hline 5 & 5 & $49 \cdot 00$ & $1 \cdot 140$ & $3 \cdot 22$ & $0 \cdot 376$ & $24 \cdot 00$ & 0.707 \\
\hline 6 & 4 & $52 \cdot 25$ & $2 \cdot 750$ & $3 \cdot 50$ & $0 \cdot 220$ & $24 \cdot 50$ & $1 \cdot 550$ \\
\hline 7 & 4 & $52 \cdot 75$ & $2 \cdot 020$ & $4 \cdot 00$ & 0.874 & $23 \cdot 25$ & 0.946 \\
\hline 8 & 9 & $53 \cdot 78$ & 0.997 & $3 \cdot 52$ & $0 \cdot 241$ & $25 \cdot 67$ & 0.726 \\
\hline 9 & 4 & $54 \cdot 00$ & $1 \cdot 220$ & 3.93 & $0 \cdot 144$ & $24 \cdot 75$ & $1 \cdot 600$ \\
\hline
\end{tabular}

Analysis of variance $\dagger$

$\begin{array}{llll}\text { Error d.f. } & 134 & 135 & 135 \\ \begin{array}{l}\text { Variance } \\ \text { ratio }\end{array} & 1.73 & 0.85 & 1.62 \\ P & 0.096 & 0.563 & 0.123\end{array}$

$\dagger$ One way analysis of variance by farm.

their flocks. The positive relationship between fat and live weight may cause conflicts between the objectives of increasing weight whilst reducing fat levels in marketed progeny. Simm (1986) noted that selection on estimated lean percentage is likely to reduce carcass weight at a given age. Secondly, the impact of selection for reduced fat depth on the 'hardiness' of hill ewes should be examined. Thus, the development of selection indices for Welsh Mountain sheep, in which fat and muscle depth are incorporated, should ensure a balance between the breeding objectives of increased sale value of market lambs and retention of essential breeding ewe characteristics, particularly their ability to survive and maintain production whilst grazing unimproved hill pastures. The importance of the breeding ewe to the viability of hill sheep production systems has been noted (Croston and Pollott, 1985). Although the concept of 'hardiness' is difficult to define it is likely that facets of it are genetically controlled. For example, Slee (1978) suggested the existence of genetically determined physiological effects on cold resistance in sheep. However, Slee and Stott (1986) suggested that improvements in cold resistance, by selection for this trait, may not be associated with increase in birth weight and ewe size. It may therefore be possible to select on the basis of fat and muscle depths without affecting ewe 'hardiness'. The possible impact on the characteristics and market value of draft hill ewes may also be of relevance since these are an important source of income in hill flocks.

It is hoped that the live weight and condition of the ewe lambs described here can be monitored to assess the relationship between ewe lamb fat and muscle depths 
and subsequent condition and lifetime productivity. It is also envisaged that the fat and muscle depths of the progeny of the CAMDA rams and ewe lambs can be recorded. The database assembled can then be used to examine in more detail the genetic correlations and heritabilities of these traits and to assist in the development and assessment of a suitable selection index for ewes and rams in hill flocks.

\section{ACKNOWLEDGEMENTS}

We are indebted to CAMDA Cynwyd Ltd for allowing access to flock data and to the commercial flock owners for their cooperation. We gratefully acknowledge the assistance and cooperation of farm and technical staff at CAMDA Cynwyd Ltd and at the University College Farm.

\section{REFERENCES}

Bennett, G. L. 1989. Path analysis and robust prediction of lamb carcass composition. Animal Production 48: 139-148.

Croston, D. and Pollott, G. 1985. Planned Sheep Production. Collins, London.

Harvey, W. R. 1985. User's Guide for LSMLMW. Ohio State University.

Kempster, A. J. 1989. Carcass and meat quality research to meet market needs. Animal Production 48: $483-496$.
Kempster, A. J., Croston, D., Guy, D. R. and Jones, D. W. 1987. Growth and carcass characteristics of crossbred lambs by ten sire breeds, compared at the same estimated carcass subcutaneous fat proportion. Animal Production 44: 83-98.

Meat and Livestock Commission. 1989b. Lean meat production. In Sheep Yearbook, pp. 81-85. Meat and Livestock Commission, Milton Keynes.

MEat and Livestock Commission. 1989a. Sheep breeding. In Sheep Yearbook, pp. 69-80. Meat and Livestock Commission, Milton Keynes.

Parrat, A. C. and Simm, G. 1987. Selection indices for terminal sires to improve lean meat production from sheep in the United Kingdom. Animal Production 45: 87-96.

Simm, G. 1986. Economic selection indices for lean meat production in sheep. Proceedings of the 3rd World Congress on Genetics Applied to Livestock Production, Vol. IX, pp. 541-546.

Simm, G. and Dingwall, W. S. 1989. Selection indices for lean meat production in sheep. Livestock Production Science 21: 223-233.

Simm, G., Young, M. J. and Beatson, P. R. 1987. An economic selection index for lean meat production in New Zealand sheep. Animal Production 45: 465-475.

SLEE, J. 1978. The effects of breed, birthcoat and body weight on the cold resistance of newborn lambs. Animal Production 27: 43-49.

SleE, J. and StotT, A. W. 1986. Genetic selection for cold resistance in Scottish Blackface lambs. Animál Production 43: 397-404. 